\title{
RARE CONDITION: PRESERVATION ASSESSMENT FOR RARE BOOK COLLECTIONS
}

IT IS NOT UNCOMMON for a university to house its special collections library in the "old" library building. The character of the architecture and the connection with the university's past often fit with the mission of collecting and preserving rare books, manuscripts, and university archives. A beautiful old library can inspire both librarians and researchers. However, it also can be the downfall of the very collections we treasure. Many older libraries now housing rare and valuable special collections materials have out-of-date and inadequate environmental control systems, if they have any at all. The resulting environmental conditions, particularly wide fluctuations in temperature and relative humidity, hasten deterioration of the collections, and librarians will need to take several steps to preserve these materials. But in order to set preservation priorities for space and collections, librarians must first study collection condition in order to evaluate needs.

The University of Tennessee Special Collections Library faces just such a situation. Located in the James D. Hoskins Library, which served as the main campus library from 1932 to 1986, the Special Collections Library is perhaps typical of many special collections. It was founded relatively recently, is housed in an older facility, and has substantial holdings that were originally part of private and/or circulating collections. In 2004, the Preservation Office, Special Collections staff, and two information science graduate students collaborated to conduct environmental and physical condition assessments of the special collections' stacks, where the rare books are housed, an area holding the university's most valuable collections and a high priority for environmental improvements. The methodology used, particularly for the collection condition survey, can by applied by other special collections libraries, for both local planning and comparative purposes. 


\section{Literature Review}

Numerous articles review the purpose, methodology, and results of collection condition surveys for circulating collections. The 1970s saw publication of the first articles discussing condition surveys of circulating materials, and several more were published in the following decades. Stanford University's Green Library conducted a landmark survey in 1979, and other academic libraries, such as Yale and Syracuse built on Stanford's methodology to conduct comparable surveys. ${ }^{1-3}$ The early studies focused on the acidity and brittleness of paper and the overall physical condition of the volumes. Preservation librarians and administrators used the resulting data to develop strategies for saving rapidly deteriorating material. The methodology can be adapted to suit most libraries and were used to focus on various aspects of a collection's physical condition, as the University of Illinois at Urbana-Champaign and the University of Tennessee completed more recently. ${ }^{4,5}$

Although the condition survey methodology developed in the past thirty years is adjustable for almost any collection of books, a survey of rare books requires a shift in methodology and focus. Unfortunately, published papers devoted to condition surveys of rare books are conspicuously lacking, leaving librarians hoping to survey rare book collections with no specialized methodology to follow. We found no articles detailing a methodology for conducting a condition survey of a rare book collection. Although some articles discuss guidelines for selecting rare books for conservation, they do not provide a methodology for a condition survey of an entire rare book collection. ${ }^{6}$ A handful of published pieces cover survey methodology and results for nonbook formats. For example, Robert S. Allen describes assessing the physical condition of maps at the Purdue University Libraries, demonstrating how method-

1. Ross Harvey, Preservation in Libraries: A Reader (London: Bowker-Saur, 1993), 79.

2. Gay Walker, Jane Greenfield, John Fox, and Jeffrey S. Simonoff, "The Yale Survey:A Largescale Study of Book Deterioration in the Yale University Library, College \& Research Libraries 46, no. 2 (Mar. 1985): 111-32.

3. Randall Bond, Mary DeCarlo, Elizabeth Henes, and Eileen Snyder, "Preservation Study at the Syracuse University Libraries," College and Research Libraries 48, no. 2 (Mar. 1987): 132-47.

4. Thomas H.Teper and Stephanie S.Atkins, "Building Preservation:The University of Illinois at Urbana-Champaign's Stacks Assessment," College and Research Libraries 64, no. 3 (2003): 211-27.

5. Mary Ellen Starmer and Dea Miller,"Surveying the Stacks: Collecting Data and Analyzing Results with SPSS," Library Resources and Technical Services 48, no. 4 (2004): 263-72.

6. Lisa B.Williams, "Selecting Rare Books for Physical Conservation: Guidelines for Decision Making," College and Research Libraries 46, no. 2 (Mar. 1985): 153-59. 
ologies from traditional collection condition surveys can be adapted, but his focus is, of course, on maps rather than rare books. ${ }^{7}$

The lack of available information results in librarians reinventing the wheel each time they plan a condition survey of rare books. This article serves to aid those librarians looking for a starting point in assessing the condition of their rare book collection. The methodology detailed below can be adapted for use in any library. The authors encourage other librarians to share their results and describe how they adapted and improved this methodology to build on the emerging best practices for the benefit of their colleagues.

\section{University of Tennessee's Special Collections}

As is true for many special collections at similar universities, the University of Tennessee's Special Collections Library is home to an array of unique and rare books that holds significance locally, regionally, and nationally. It was formed in the 1950s and includes manuscripts, rare books, and the university archives. The rare book collection comprises more than 50,000 volumes dating from 1481 to the present, with the majority of the holdings being nineteenth- and twentieth-century volumes. Collection strengths are Tennesseana, Appalachian history, North American Indians, nineteenth-century American literature, early voyages and travels, and early imprints. The American history portion of the collection concentrates from 1820 to 1870, the period embracing the presidencies of Tennesseans Andrew Jackson, James K. Polk, and Andrew Johnson. ${ }^{8}$ The rare book collection holds definitive works by English playwright William Congreve and English novelist Jane Austen. It also includes a growing number of eighteenth- and nineteenth-century hymnbooks and shape note songbooks and medical books published in the same period.

\section{Environmental Conditions}

For a collection of rare and valuable materials, the environment should ideally be well regulated and within the recommended parameters in temperature, relative humidity, and light levels. These factors have a

7. Robert S.Allen, "Map Collection Physical Condition Assessment Survey Methodology and Results," Bulletin: Special Libraries Association, Geography and Map Division 184 (fall/winter 1996): 11-27.

8. "The Special Collections Rare Book Unit," University of Tennessee Libraries Special Collections.Available online from http://www.lib.utk.edu/spcoll/front_page/rare_books.html. 
profound effect on the deterioration rate of library materials, and even slight damage to a rare book is highly significant. Light, both visible and ultraviolet, can cause photochemical deterioration, a type of chemical reaction in paper that leads to irreparable damage. High temperatures and relative humidity $(\mathrm{RH})$ above or below the recommended range also speed the rate of deterioration in books and can lead to mold growth. Fluctuations in temperature and $\mathrm{RH}$ also can cause serious damage.

The rare book collection at the University of Tennessee is subjected to all the above conditions. To determine the current levels of temperature, $\mathrm{RH}$, and light to which the rare books were exposed and to asses the long-term effects of those factors, the preservation coordinator conducted an environmental survey. The first element examined was light. Using a light meter to measure visible and ultraviolet light, the preservation coordinator determined that parts of the collection are constantly subjected to UV levels four times the recommended limit of 75 microwatts per lumen. ${ }^{9}$ Due to past renovations of the building, the nonfiltered fluorescent lights in the stacks area cannot be turned off without also turning off lights in other occupied parts of the building, and this constant exposure is detrimental to the collection over time.

Preservation staff collected data regarding the temperature and $\mathrm{RH}$ in the room. The data collection was accomplished with the Preservation Environment Monitor and analyzed using Climate Notebook software, both of which were developed through NEH funding by the Image Permanence Institute at the Rochester Institute of Technology. The mean temperature from April 2004 to February 2005 was 73 degrees, five degrees higher than the commonly accepted upper limit, and the temperature was only in the target range of 64 to $70^{\circ} \mathrm{F}$ for two percent of the time. Fluctuations in the temperature were common, with as much as $5^{\circ}$ fluctuation in one day. The RH fluctuated even more widely, with dramatic shifts during the winter months. Humidity levels also were often dangerously low during the winter months, dropping to as low as 8 percent at times, causing further damage to the collection. The $\mathrm{RH}$ was only within the target range of 42 to 48 percent for 18 percent of the time. Another alarming number is the Time-weighted Preservation Index (TWPI), which estimates the life expectancy of the materi-

9. Sherelyn Ogden, "Temperature, Relative Humidity, Light, and Air Quality: Basic Guidelines for Preservation," in Preservation of Library and Archival Materials, ed. Sherelyn Ogden (Andover, Mass.: Northeast Document Conservation Center, 1999), 71. 
als, based on the environmental conditions data collected over a period of time. The TWPI for the rare books collection is forty-five years, a surprisingly short time period for a valuable collection. (See appendix A.)

It is widely understood that these conditions accelerate deterioration in library and archival materials. Housing a university's most valuable library materials in such an environment is hazardous. For any library in this situation, a renovation of the current space or relocation of the collection are two possible solutions to the problem. To assess the current physical condition of those materials and bring to light any damage caused by the environment, a library needs to conduct a collection condition survey. This was the next step for the University of Tennessee.

\section{Methodology and Procedures}

Libraries often conduct collection condition surveys in two phases, the planning and pilot phase and the full survey and analysis phase. Tennessee conducted both phases over an eight-month period from January to August 2004. The project was assisted by two graduate students from the University of Tennessee's School of Information Science in threecredit hour practicums. At the time of their survey work, both students had completed the core curriculum required for the master's of information science as well as a course on the preservation of library and archival materials. The student who completed the full survey also had more than a hundred hours of practical experience in the library's Conservation Lab and Preservation Office. This experience and education was essential to ensure that the survey team could carry out the study proficiently. Although the graduate students conducted the hands-on work of the survey, they were directed by the library's preservation coordinator and the interim head of special collections to develop a questionnaire and evaluate the results of the survey. Thus, the survey team consisted of the preservation coordinator, the interim head of special collections, and two graduate students, each of whom worked on one phase of the project.

Given the lack of pertinent literature, the rare book survey methodology was adapted from other surveys conducted at the University of Tennessee Libraries. These past surveys include the Hodges Library, the Agriculture and Veterinary Medical Library, and the Music Library, where collection condition surveys were conducted in 2002 and 2003. For these surveys, a preservation survey team developed a Web-based survey form 
and used SPSS software for data capture and analysis. As described in "Surveying the Stacks: Collecting Data and Analyzing Results with SPSS," use of these tools made the work more efficient and accurate. ${ }^{10}$ The survey was hosted on a server monitored by the university's Statistical Consulting Center and made accessible via an internal university Web site. Libraries with similar collections should be able to adapt the methodology detailed here for local surveys.

UT's rare book collection consists of approximately 50,000 volumes. With the help of experts from the university's Statistical Consulting Center, preservation and special collections determined that 660 volumes would constitute a statistically significant sample size. A sample of 663 volumes was randomly selected by a program written for the Ex Libris, the library's integrated library system. The sample list was put into an Excel file and printed. Anticipating that some volumes would not be available when the survey was conducted, the survey team decided to draw the volume directly to the right of the missing volume if the sample item was not on the shelf.

Before beginning the full survey, the team conducted a pilot survey to test the Web-based form and the appropriateness of the techniques used to assess the collection. For this trial run, a random sample of 108 volumes was drawn from the library database and a graduate student conducted the survey, taking approximately four hours over four weeks to finish. Upon completion, the student and the preservation coordinator reviewed the results and made changes to the survey form, altering and adding questions to improve clarity and the overall quality of the survey. For example, because commercial binding was found to be a previous treatment in some of the volumes from the pilot survey, the final survey included "binding" as a type of previous treatment.

A second graduate student completed the final survey of the 663 sample volumes in approximately 130 hours. The online survey form consisted of sixteen screens. Depending on responses to some questions, however, certain screens could be skipped if they were not relevant to a particular book. For example, if the volume did not have a protective enclosure, the online form automatically skipped the question about the condition of the enclosure. (See appendix B.) 


\section{Analysis}

Upon completion of the final survey, the team began analysis of the results. The report function in SPSS provided the means for extracting numbers and percentages for each question asked in the survey. The survey team then compiled easy-to-read tables in Microsoft Word to share with colleagues in the university. Some examples of these tables are shown below in a brief examination of results.

\section{Publication Dates}

A distribution of publication dates is necessary for understanding the nature of the collection. The papermaking process changed dramatically in the mid-nineteenth century, thus altering the chemical composition of the paper in most books and the way in which they deteriorate over time. There was no publication date in more than a hundred of the volumes surveyed. Of the volumes with publication dates, 32 percent were published between 1553 and 1850, 18 percent between 1851 and 1900, 22 percent between 1901 and 1950, and 28 percent between 1951 and 2002 .

\section{Shelving}

Of the 663 volumes sampled, 19 had one or more shelving problems. Three were shelved in the wrong location, eight were not shelved straight, and another eight were shelved too tightly. Fortunately, improper shelving is not a significant issue for rare book collections as less than three percent of the random sample had shelving problems. The low statistical outcome is in large part due to the closed stacks of the rare book room and well-trained staff who locate, pull, and reshelve items.

\section{Type of Leaf Attachment}

The most common type of leaf attachment was sewn through the folds as more than 74 percent of the volumes were made with the classic and durable bookbinding method. At a distant second, less than 10 percent of the samples were stapled, by perfect binding, double-fan adhesive binding, oversewing, and spiral construction. Therefore, the large percentage of those sewn through the fold as a leaf attachment method correlates with the age of the items in the survey and the history of book assembly. 


\begin{tabular}{|l|r|r|}
\hline Leaf attachment & No. & \multicolumn{1}{c|}{$\%$} \\
\hline Double-fan adhesive & 13 & 1.96 \\
\hline Perfect & 44 & 6.64 \\
\hline Sewn through folds & 492 & 74.21 \\
\hline Oversewn & 7 & 1.06 \\
\hline Spiral & 5 & .75 \\
\hline Stapled & 63 & 9.5 \\
\hline Saddle stitched & 26 & 3.92 \\
\hline Other & 13 & 1.96 \\
\hline
\end{tabular}

\section{Type of Volume}

Monographs represented 398, or 60 percent of the sample. A large portion, 23 percent of the items surveyed, were part of a multivolume set.

\section{Type of Binding}

The vast majority of the volumes, 62 percent, were publisher hardbacks followed by publisher paperbacks at 20 percent, other bindings, and pamphlets. Other types of binding included commercial binding and single sheets lain together.

\section{Enclosures}

Items from the survey with protective enclosures totaled 26 percent. Of those enclosures, 43 percent were unsatisfactory (i.e., the enclosure was in poor condition, acidic, or both).

\section{Dust Jackets}

Of the sampled volumes, 26 percent had dust jackets, of which 51 percent were in good condition and 47 percent in fair condition. Items with Mylar book jackets totaled only one percent of the collection surveyed.

\section{Condition of Binding and Text Block}

The surveyor could select multiple condition options. The results of the condition questions reflect the type of collection being surveyed. Due to the nature of the collection, red-rot leather damage was common. Most of the volumes, 54 percent, had some type of damage to the binding and/or text block, and there were 998 total occurrences of the different types of damage. There were 188 torn end sheets, 139 damaged spines, 132 loose pages, 
and 94 loose hinges. Other damage included broken text block, missing cover, red-rot leather, loose cover(s), and damaged pages (not mutilation).

\begin{tabular}{|l|r|r|}
\hline Condition of Binding and Text Block & No. & \multicolumn{1}{|c|}{$\%$} \\
\hline Broken text block & 78 & 12 \\
\hline Missing covers & 49 & 7.4 \\
\hline Red-rot leather & 88 & 13.3 \\
\hline Damaged spine & 139 & 21 \\
\hline Loose hinges & 94 & 14.2 \\
\hline Damaged covers & 108 & 16.3 \\
\hline Missing pages (not mutilation) & 6 & 1 \\
\hline Damaged pages (not mutilation) & 38 & 5.8 \\
\hline Loose pages & 132 & 20 \\
\hline Torn end sheets & 188 & 28.4 \\
\hline Loose covers & 78 & 11.5 \\
\hline No damage & 305 & 46 \\
\hline
\end{tabular}

\section{Environmental Damage}

Environmental damage proved to be substantial, as 71 percent of the items had some form of damage from its present and/or past environment. Most of the volumes, 63 percent, had at least mild to moderate amounts of dust. Mild UV damage was found in over 21 percent of the volumes whereas just over one percent had extreme UV damage. Water damage was obvious in more than six percent of the items surveyed. However, it is difficult to judge whether the water stains were the result of environmental conditions, patron use, or past storage environments. Mold was found on less than one percent of the items whereas insect damage was found on more than one percent of the items. The mold and insect damage could also be the result of storage and use prior to ownership by special collections.

\begin{tabular}{|l|r|r|c|r|}
\hline $\begin{array}{l}\text { Type of } \\
\text { Environmental } \\
\text { Damage }\end{array}$ & $\begin{array}{c}\text { Mild to } \\
\text { Moderate } \\
\text { No. }\end{array}$ & \multicolumn{1}{c|}{$\%$} & $\begin{array}{c}\text { Extreme } \\
\text { No. }\end{array}$ & $\%$ \\
\hline Mold & 3 & .5 & 2 & .3 \\
\hline Ultraviolet light & 141 & 21.3 & 9 & 1.3 \\
\hline Dust & 417 & 63 & 3 & .35 \\
\hline Insect & 11 & 1.6 & 0 & 0 \\
\hline Water & 37 & 5.58 & 4 & .6 \\
\hline
\end{tabular}




\section{Patron Damage}

Evidence of patron damage was found in only eight percent of the collection surveyed, and there were fifty-eight total instances of different types of damage. Pencil markings were the most common, followed by a few instances of ink, food and drink stains, adhesive damage, dog-eared pages, and pages torn or removed. Again, it is difficult to judge whether this damage is from patron or owner use or environmental conditions. Most patron damage more than likely occurred before ownership by special collections where materials enjoy the benefits of closed stacks and constant monitoring of patrons in the reading room by staff members. Although the student examining the volumes did not include markings, such as signatures and margin notes obviously made by a previous private owner, it was often difficult to judge the circumstances under which some markings were made.

\begin{tabular}{|l|r|r|r|r|}
\hline Type of Damage & $\begin{array}{c}\text { Mild to } \\
\text { Moderate } \\
\text { No. }\end{array}$ & \multicolumn{1}{c|}{$\%$} & $\begin{array}{c}\text { Extreme } \\
\text { No. }\end{array}$ & $\%$ \\
\hline Pencil & 20 & 3 & 2 & .3 \\
\hline Ink & 4 & .6 & 0 & 0 \\
\hline Highlighter & 1 & .2 & 0 & 0 \\
\hline Paper clips & 0 & 0 & 0 & 0 \\
\hline Dog-eared & 6 & 1 & 0 & 0 \\
\hline Post-it notes & 0 & 0 & 0 & 0 \\
\hline Bookmarks and other & 0 & 0 & 0 & 0 \\
papers & \multicolumn{1}{c|}{0} & .5 & 0 & 0 \\
\hline Pages torn or removed & 3 & 0 & 0 & 0 \\
\hline Animal damage & 0 & 2.7 & 0 & 0 \\
\hline Food or drink stains & 18 & .6 & 0 & 0 \\
\hline Adhesive & 4 & & & \\
\hline
\end{tabular}

\section{Gutter Margin Width}

For a volume to be rebound without losing text, it must have a gutter margin of at least one-quarter inch, and a sufficient margin also facilitates conservation treatments. Of the volumes surveyed, more than 99 percent had margins of one-quarter inch or wider.

\section{Previous Repairs}

Ten options were available, and multiple boxes could be checked in the previous treatment section of the form. Previous in-house repairs found 
while completing the survey include spine replacement (2\%), page mends $(1 \%)$, and end sheet replacement and pages photocopied (both less than 1\%). Enclosures were previously made for 19 percent of the items surveyed, even though the enclosures may have been unsatisfactory. Out-of-house treatments included commercial binding (11\%) and photocopied/reformatted (1\%) materials. From the random sample, 12 percent were treated and repaired out-of-house.

\section{Treatment Recommendation}

Treatment was recommended for 53 percent of the surveyed collection. To protect fragile dust jackets, 21 percent of the items surveyed need a Mylar book jacket and more than 18 percent need a custom-made box. Other recommendations were to pamphlet-bind with an envelope and send the item to a conservator. The items with no treatment recommendations were in good condition (some having had previous treatment).

\begin{tabular}{|l|r|r|}
\hline Treatment Recommendation & \multicolumn{1}{|c|}{ No. } & \multicolumn{1}{c|}{$\%$} \\
\hline Box & 121 & 18.25 \\
\hline Pamphlet bind with envelope & 85 & 12.8 \\
\hline Send to conservator & 3 & .45 \\
\hline Mylar book jacket cover & 139 & 21 \\
\hline Does not need treatment & 315 & 47.5 \\
\hline
\end{tabular}

\section{Discussion}

As is true in most special collections, analysis of collection condition data will likely indicate a wide spectrum of issues. Many challenges must be expected from collections composed of antique materials. For example, 54 percent of the volumes surveyed at Tennessee showed damage to the binding and/or the text block. This is a large percentage, but many of these volumes are centuries old and came from other circulating collections or private homes. It is probable that some or most of the damage to the binding and text block occurred before the volumes were added to the rare book collection. That does not negate, however, the need for staff and user education or treatment. Teaching staff and users proper handling techniques is an important part of preventing damage from occurring. Most of the recommended treatments can be carried out in-house; however, it may be more efficient to outsource some of the custom boxes to a bindery or conservation lab. If all the work is done in house, resources will be needed for the conservation unit, including 
staff, supplies, and equipment. Either option requires an increase in funding.

When the library has a poor physical environment, this will become readily apparent in the responses to environmental damage questions. As discussed earlier, light, temperature, and relative humidity levels in the University of Tennessee special collections are dangerous. The fluorescent lighting is most likely a major factor in the UV damage found in more than 22 percent of the volumes. Evidence of mold also was found on five volumes. This is alarming but does not constitute a crisis. The mold discovered is old, dormant growth, and it has been cleaned. It is not a current outbreak, but the survey team cannot say for certain when the mold occurred. It may have been on the books when they were added to the collection.

Most special collections do not record specific notes about the condition of printed volumes added to the collection. And after a volume is added, it is hard to know when some types of damage, such as the above-mentioned light and mold damage, occurred, but any adverse current conditions in the library will exacerbate the problem. To support future decision making about the collection and storage environment, a library could add information to the catalog database about the condition of each book upon receipt.

However, the source of some environmental problems can be pinpointed. A surprising aspect of the environmental section of the UT survey was the number of dusty volumes. The collection was dusted four months before the final survey was completed; thus, the data point to an inadequate filtration system that should be addressed in any renovation plan.

Positive results also can be found in survey data and used by the library as examples of current good practices. The survey at UT pointed to good shelving practices employed by the special collections staff, a collection that is predominantly composed of long-lasting sewn-through-the-fold bindings, and a low occurrence of patron damage and mutilation. Although the environmental conditions are far from adequate, these volumes are usually handled properly by special collections staff and patrons. Good stewardship such as this can be a foundation for further improvements that require external funding.

Libraries have much to gain by conducting an evaluation of the environmental conditions in special collections. A random survey of rare books 
to assess physical condition will illustrate areas of both weakness and strength. A trial run of the collection survey methodology and instrument ensures an efficient and accurate assessment. It also is important for those conducting the survey to have experience and training in preservation. An online survey form connected to data analysis software increases speed and accuracy in collecting and synthesizing data. With a documented understanding of the library's strengths and weaknesses regarding the condition of the collection, librarians can draw on the results for planning and justifying improvements.

Based on the survey results, it is now readily apparent why a renovation of special collections must be a priority for UT Libraries. A renovation will improve the lighting, temperature, and relative humidity and will provide for a filtration system, all of which will preserve the university's rare and valuable materials for generations to come. A second outcome of the survey results provides for an allocation of resources for conservation treatments. Long-term planning for conservation expertise or suitable outsourcing is needed, and the condition survey will be the initial guiding force in bringing attention to the issue. Moreover, preservation staff may conduct a more in-depth survey of the collection or parts of the collection to further focus on certain aspects of the findings. More generally, the survey team anticipates that the results from the surveys will be used as specific statistical support for future funding requests.

\section{Conclusion}

Assessment is often listed as the first step in planning for any preservation program. Rare book collections differ in many ways from circulating collections, but because they are rare, they should be a top priority for preservation. Just as collection condition surveys are useful tools for setting priorities in circulating collections, so too are they a practical starting point in the preservation planning process for rare books. With a clear picture of the situation and its challenges, a library will be better able to budget and plan for the care of the collection.

We believe the results from the University of Tennessee's special collections survey provide baseline data (for similar collections) or at least significant comparative data for other special collections surveys, and other libraries may find our survey methodology to be a useful starting point. We look forward to seeing more published results from similar surveys that will give the special collections community a fuller picture of the variety and range of preservation challenges facing special collection libraries today. 


\section{Appendix A}

The charts below reflect data collected by a Preservation Environment Monitor and analyzed using Climate Notebook software, both developed by the Image Permanence Institute at the Rochester Institute of Technology. The target temperature and $\mathrm{RH}$ ranges are marked by solid horizontal lines.
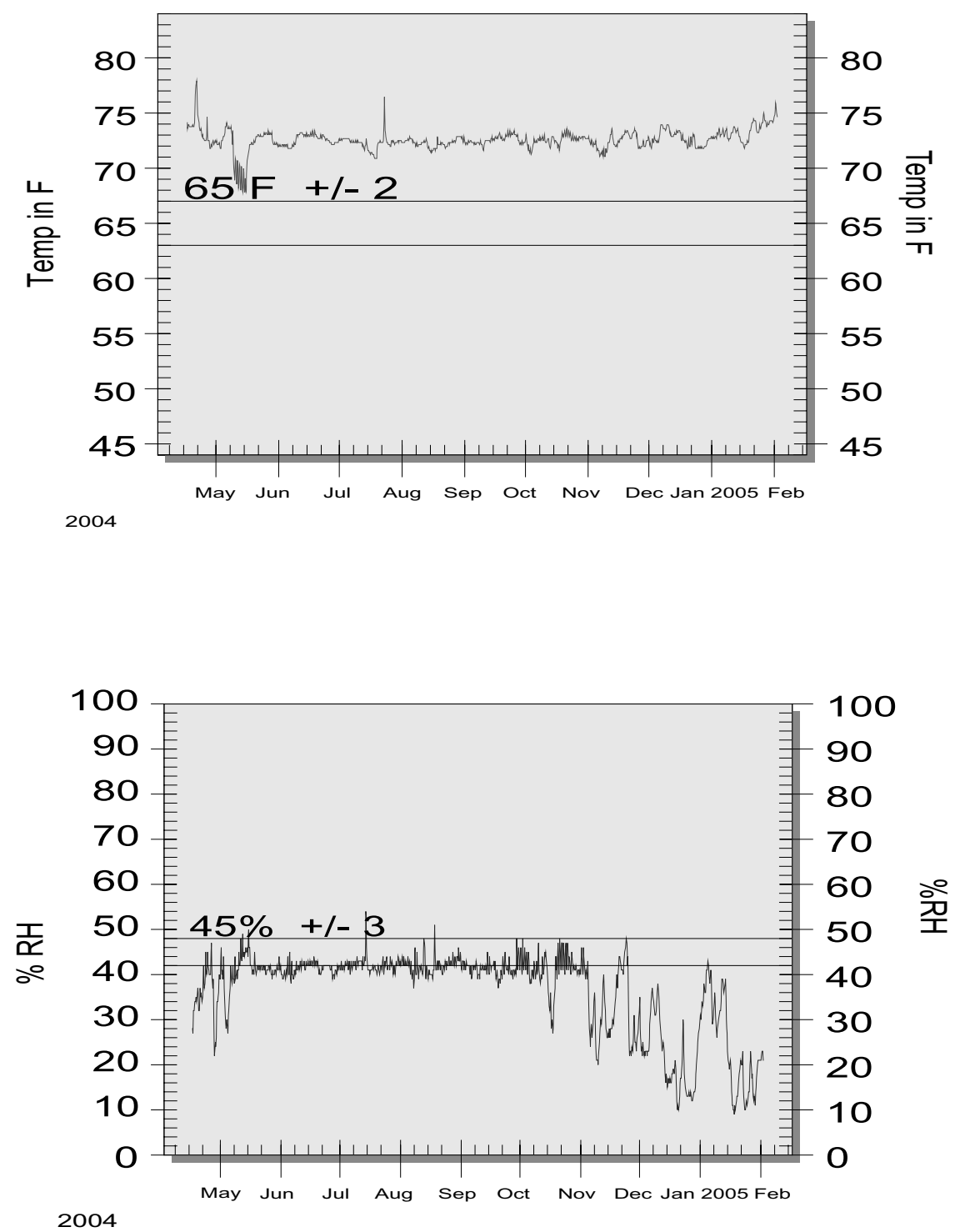


\section{Appendix B}

\section{Survey Form}

1. Note call number

Bar code

Note shelf

Year of publication

Place of publication

2. Is this volume shelved

correctly?

Shelved in wrong location

Not shelved straight

Shelved on spine

Shelved on fore-edge

Shelved too tightly

3. Leaf Attachment

Double-fan adhesive

Perfect

Sewn through folds

Oversewn

Spiral

Stapled

Saddle stitched

Other

Other type of leaf attachment

Type of Volume

Monograph

Part of multivolume set

Periodical

Other

Other type of volume

Type of Binding

Published hardback

Publisher paperback

Pamphlet

Other

Other type of binding

4. Is volume in a protective

enclosure?

Yes/No
5. Is enclosure satisfactory?

Yes/No

6. Is there a dust jacket?

Yes/No

7. Mylar cover?

Yes/No

8. Condition of dust jacket

Good

Fair

Poor

9. Condition of Binding and Text Block

Check all that apply:

Broken text block

Detached or missing covers(s)

Red-rot leather

Torn spine

Loose hinge(s)

Damaged cover(s)

Missing pages (not mutilation)

Damaged pages (not

mutilation)

Loose pages

Torn end sheets

Loose cover (s)

Warped

No Damage

10. Environmental Damage

Yes/No

11. Rate the following as none, mild-moderate, extreme:

Mold

UV

Dust

Insect

Water

Other

If other, please specify 
12. Mutilation and Patron Damage Yes/No

13. Rate the following as none, mild-moderate, extreme:

Pencil

Ink

Highlighter

Paper clips

Dog-ears

Post-it notes

Bookmarks and other paper Pages torn or removed

Animal damage

Food or drink stains

Adhesive

Other

If other, please specify

14. Gutter Margin Width

$1 / 4$ inch or wider

Less than $1 / 4$ inch
15. Previous Treatments

Spine replacement

Tip-in

Hinge-tightening

Page mends

End sheet replacement

Pages photocopied

Binding

Photocopied/reformatted

Enclosure made

No previous treatment

16. Treatment Recommendation

Box

Pam binder with envelope

Send to conservator

Mylar book jacket cover

Does not need treatment

17. Additional Comments 


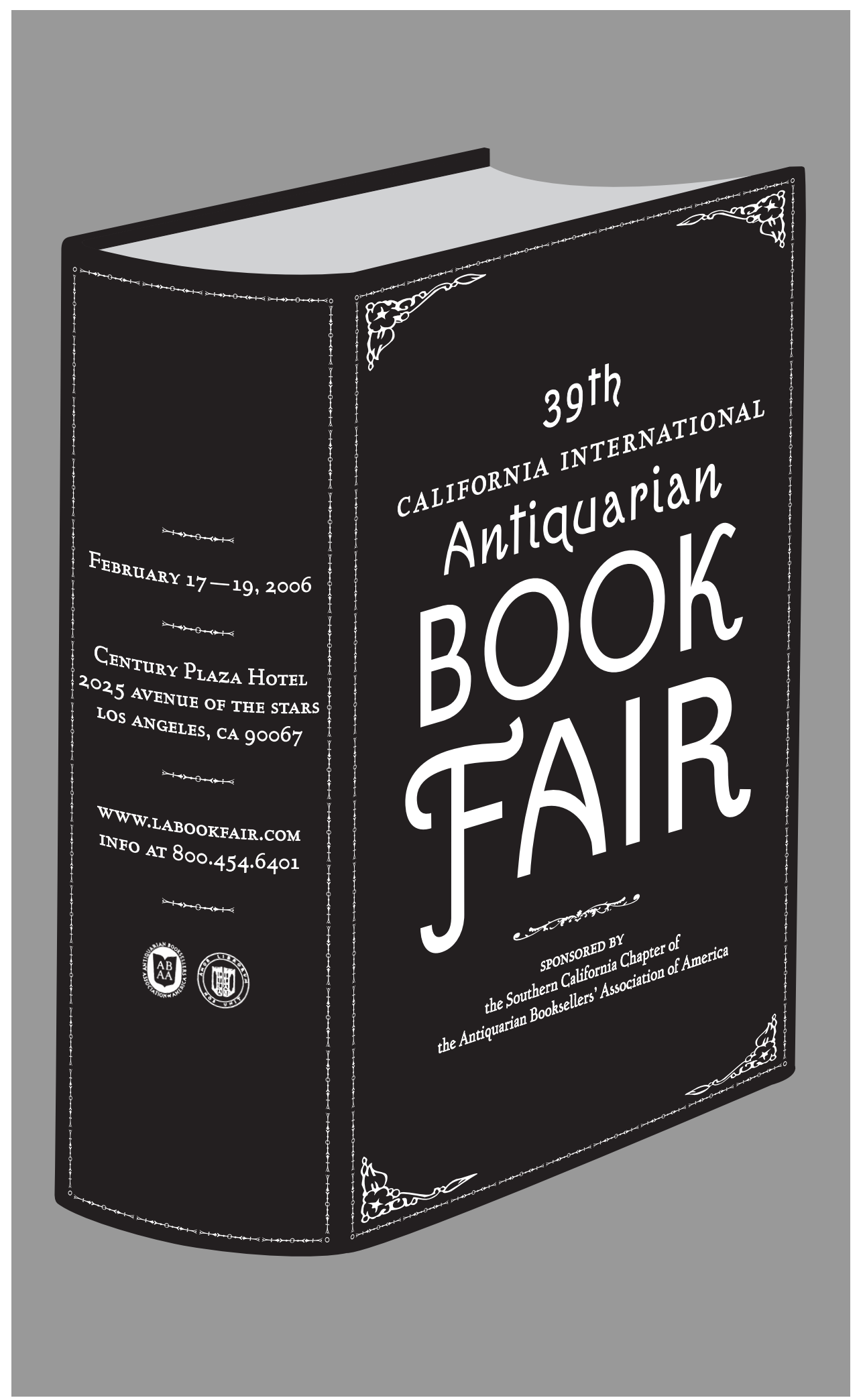

